\title{
Cap-assisted endoscopy: Do we have enough evidence?
}

\section{다 (1) $(2)$}

\author{
Author \\ Thomas Frieling
}

Institution

Department of Gastroenterology, Hepatology, Infectiology, Neurogastroenterology, Hematology, Oncology, and Palliative Medicine, HELIOS-Clinic Krefeld, Krefeld, Germany

\author{
Bibliography \\ DOI https://doi.org/10.1055/a-0650-4544 | \\ Endoscopy International Open 2018; 06: E1224-E1226 \\ (c) Georg Thieme Verlag KG Stuttgart · New York \\ ISSN 2364-3722 \\ Corresponding author \\ Thomas Frieling, MD, Medizinische Klinik II, Dept. of \\ Internal Medicine with Gastroenterology, Hepatology, \\ Infectiology, Neurogastroenterology, Hematology, \\ Oncology and Palliative Medicine, HELIOS-Clinic Krefeld, \\ 47805 Krefeld, Lutherplatz 40, Germany \\ Fax: 0049-(0)2151-322078 \\ thomas.frieling@helios-kliniken.de
}

\section{ABSTRACT}

So, is there enough evidence to incorporate $C \mathrm{C}$ in clinical practice? If we interpret the literature and the meta-analysis by Nutalapati et al., the answer for the clinically-focused endoscopist, with regard to adenoma detection rate (ADR), at present, may be "no". Significant differences do not necessarily imply clinical benefits and translation into clinical practice. The answer for the improvement of cecal intubation frequency and intubation time by the cap depends on the focus of training commitment, because these effects of the cap may be beneficial, especially for unexperienced endoscopists. It is obvious that further studies are needed. In this line, it is interesting to know, that in a recent metaanalysis of prospective studies, the length of the transparent cap had opposite effects on investigation time and polyp detection rate. Whereas, the anal to cecal time was significantly shortened by a cap length of $>7 \mathrm{~mm}$ and a polyp detection rate was significantly improved by a cap length of $<4 \mathrm{~mm}$.
It seems to be important that future studies on the clinical benefit of cap-assisted colonoscopy must also control for other factors affecting ADR, such as indication for colonoscopy, the experience of the investigator, the presence of diverticulosis, the quality of bowel cleansing, the forward and withdrawal time, the polyp/adenoma size, and the location of mucosal lesions as well as the sedative medication applied during colonoscopy. Just elaborating the literature does not solve the problem.

In this issue of Endoscopy, Nutalapati et al. [1] present a meta-analysis on the performance of cap-assisted colonoscopy (CC) for adenoma detection rate (ADR) during standard colonoscopy (SC). By extensive literature search (Medline, Embase, Scopus, Cochrane and Web of Science databases, abstracts published at national meetings), they analyzed and included only high-quality studies with Jadad score $\geq 3$. The use of cap significantly improved the ADR (odds ratio [OR] 1.18, 95\% confidence interval $[\mathrm{Cl}] 1.03-1.33)$, detection of $0.16(0.02-0.30)$ additional adenomas per positive participant (APP), improved cecal intubation (OR 1.61, 95\% Cl 1.33-1.95), and decreased the cecal intubation time $(95 \% \mathrm{Cl} 0.37-1.39)$.

\section{What is the rationale for CC?}

To date, colonoscopy is the best available method to detect and to remove colorectal neoplasia and to decrease the rate of colorectal cancer-related death [2,3]. Nationwide screening colonoscopy programs indicate that the ADR of conventional colonoscopy varies between 15 and 30\% [4]. It is obvious that a significant number of small adenomas and also some advanced lesions are missed even by experienced endoscopists during SC. This has been shown both in back-to-back colonoscopy studies and in evaluations comparing virtual and optical colonoscopy in the same patients. In these reports, the miss rate of colonoscopy has been reported to be up to $48 \%$ [5-16]. Particular problems may occur with blind spots behind the semilunar folds or near the anal verge and with lesions located in the right colon [9-11] that are easily overlooked. In addition, the small but significant number of carcinomas detected within 3-5 y after an apparently normal screening colonoscopy indicates that the visualization of mucosal lesions is limited [2,17-19].

Besides CC, extension of visual field by wide-angle endoscopy, retrograde viewing device ("third eye"), transparent retractable extension device, or the newly designed full-spectrum colonoscope, the EWAVE system and the endocuff device, 
are potential options for improving the detection rate of mucosal lesions. The rational for this assumption is that only part of the whole colonic surface can be visualized during routine colonoscopy. This has been shown in a recent study [20] evaluating the visible surface of a soft resin colon by back-to-back colonoscopies in a colonic training model. Here, the inner surface was stained by a raster of dots, and the number of dots counted during colonoscopy served as an estimate for the visible surface area of each segment of the colon. Overall, $60 \%$ of the maximal countable dots were visualized by 5 experienced investigators leading to the assumption that only $60 \%$ of the inner surface was seen. In this model, extension of visual field by CC was up to $40 \%$ compared to SC, but only significant for the right colon [20]. However, this potential advantage of CC for the right coIon may have significant clinical impact because localization of tumors in the cecum or ascending colon is an independent risk factor for interval cancers after negative colonoscopy [21].

\section{What is the clinical benefit of CC?}

Data from the literature with regard to CC are controversial. In 15 randomized studies [ $22-36$ ] including 2 back-to-back studies [23,26], 1 retrospective study [37], and 1 nonrandomized study [38], 9 studies showed significant improved polyp/adenoma detection rates with CC $[22,23,26,29,30,34-37]$ whereas 7 other studies revealed no significant differences $[24,27,28,31-33,38]$ and 1 study showed a significant disadvantage of CC [25]. The parameters that were significantly superior for CC in these studies included overall polyp detection rate, polyp miss rate, total number of adenoma, polyp size $(<5 \mathrm{~mm})$, flat adenoma, and right colon. Some of these benefits were related to the experience of the investigators or difficult cases [28].

One reason for these heterogeneous findings in the literature might be that other factors that have influence on ADR, such as the indication for colonoscopy, the experience of the investigator, the presence of diverticulosis, the quality of bowel cleansing, the forward and withdrawal time, the polyp/adenoma size, and location of mucosal lesions as well as the sedative medication applied during colonoscopy, were not controlled for in most of the studies. This appears to be of clinical relevance because bowel cleansing and withdrawal time significantly affect the detection rate of mucosal lesions during colonoscopy.

In this issue of Endoscopy, Nutalapati et al. [1] try to overcome this dilemma by selecting only papers of high quality for their meta-analysis. Criteria for the "high quality" was a Jadad score $\geq 3$ [39]. However, it must be emphasized that the Jadad score is not a perfect instrument for selecting high-quality studies because it places greater emphasis on the quality of reporting as opposed to the actual methodological quality of a trial. In addition, it does not assess allocation concealment [40]. Nevertheless, even with this selection bias, the difference between CC and SC was, though significant, only minor. Whereas an initial pooled analysis of 8 randomized controlled trials (RCTs) showed no significant differences, 7 high-quality RCT revealed a significant difference (OR 1.18, $95 \% \mathrm{Cl} 1.03-$ 1.33). However, the significance was only reached by removing
1 study [26] with a Jadad score of 1 from the initial 8 RCTs [1] (Fig. 2a and Fig.2b). This significant finding is also modified by the fact that the authors excluded 3 high-quality studies $[28,30,33]$. Out of them, at least in 1 study ADR/APP could be easily calculated by the reported data and was not significant between CC and SC [33].

Nutalapati et al. [1] further analyzed the benefit of the cap on cecal intubation rate and cecal intubation time.

Therefore, they selected additional "low-quality" paper for analysis of cecal intubation rate and cecal intubation time. According to their meta-analysis, CC significantly improved cecal intubation (OR 1.61, $95 \% \mathrm{Cl} 1.33-1.95$ ) and decreased cecal intubation time by an average of 53 s ( $95 \%$ Cl $0.37-1.39)$.

Thus, is there enough evidence to incorporate CC in clinical practice? Interpreting the literature and the meta-analysis by Nutalapati et al. [1], the answer for the clinically focussed endoscopist with regard to ADR at present may be no. Significant differences do not necessarily imply clinical benefits and translation into clinical practice. The answer for the improvement of cecal intubation frequency and intubation time by the cap is depending on the focus of training commitment because these effects of the cap may be beneficial especially for unexperienced endoscopists $[27,41]$. It is obvious that further studies are needed. In this line, it is interesting to know that in a recent meta-analysis of prospective studies, the length of the transparent cap had opposite effects on investigation time and polyp detection rate [42]. Whereas the anal to cecal time was significantly shortened by a cap length of $>7 \mathrm{~mm}$, polyp detection rate was significantly improved by a cap length of $<4 \mathrm{~mm}$ [42].

It seems to be important that future studies on the clinical benefit of CC must also control for other factors affecting $A D R$, such as indication for colonoscopy, the experience of the investigator, the presence of diverticulosis, the quality of bowel cleansing, the forward and withdrawal time, the polyp/adenoma size, and the location of mucosal lesions as well as the sedative medication applied during colonoscopy. Just elaborating the literature does not solve the problem.

\section{Competing interests}

None

\section{References}

[1] Nutalapat V, Kanakadandi V, Desai M et al. Cap-assisted colonoscopy: a meta-analysis of high-quality randomized controlled trials. Endosc Int Open 2018; 06: E1214-E1223

[2] Brenner AT, Dougherty M, Reuland DS. Colorectal cancer screening in average risk patients. Med Clin North Am 2017; 101: 755 - 767

[3] Schmiegel W, Buchberger B, Follmann M et al. S3-Leitlinie - Kolorektales Karzinom. Z Gastroenterol 2017; 55: 1344 - 1498

[4] Brenner H, Altenhofen L, Kretschmann J et al. Trends in adenoma detection rates during the first 10 years of the German Screening Colonoscopy Program. Gastroenterology 2015; 149: $356-366$ 
[5] Haseman JH, Lemmel GT, Rahmani EY et al. Failure of colonoscopy to detect colorectal cancer: evaluation of 47 cases in 20 hospitals. Gastrointest Endosc 1997; 45: 451 - 455

[6] van Rijn JC, Reitsma JB, Stoker J et al. Polyp miss rate determined by tandem colonoscopy: a systematic review. Am J Gastroenterol 2006; 101: $343-350$

[7] Rockey DC, Niezwiecki D, Davis W et al. Analysis of air contrast barium enema, computed tomographic colonography and colonoscopy. Lancet 2005; 365: $305-311$

[8] von Schönfeld J, Hinzmann S. Missed colonic adenomas in routine primary care endoscopy: a prospective tandem colonoscopy study. Z Gastroenterol 2010; 48: 1207-1210

[9] Hosokawa O, Shirasaki S, Kaizaki Y et al. Invasive colorectal cancer detected up to 3 years after a colonoscopy negative for cancer. Endoscopy 2003; 35: $506-510$

[10] Bressler B, Paszat LF, Vinden C et al. Colonoscopic miss rates for rightsided colon cancer: a population-based analysis. Gastroenterology 2004; 127: $452-456$

[11] Baxter NN, Goldwasser MA, Paszat LF et al. Association of colonoscopy and death from colorectal cancer: a population-based, case-control study. Ann Int Med 2009; 150: 1-8

[12] Rex DK. Colonoscopic withdrawal technique is associated with adenoma miss rates. Gastrointest Endosc 2000; 51: $33-36$

[13] Hixson LS, Fennerty MB, Sampliner RE et al. Prospective study of the frequency and size distribution of polyps missed by colonoscopy. J Nat Cancer Inst 1990; 82: 1769-1772

[14] Imperiale TF, Glowinski EA, Lin-Cooper C et al. Five-year risk of colorectal neoplasia after negative screening colonoscopy. N Engl J Med 2008; 359: $1218-1224$

[15] Rex DK, Cutler CS, Lemmel GT et al. Colonoscopic miss rates of adenomas determined by back-to-back colonoscopies. Gastroenterology 1997; 112: $24-28$

[16] Bressler B, Paszat LF, Chen Z et al. Rates of new or missed colorectal cancers after colonoscopy and their risk factors: a population-based analysis. Gastroenterology 2007; 132: 96-102

[17] Ee HC, Semmens JB, Hoffman NE. Complete colonoscopy rarely misses cancer. Gastrointest Endosc 2002; 55: 167 - 171

[18] Leaper M, Johnston M], Barclay M et al. Reasons for failure to diagnose colorectal carcinoma at colonoscopy. Endoscopy 2004; 36: 499-503

[19] Robertson DJ, Greenberg ER, Beach M et al. Colorectal cancer in patients under close colonoscopic surveillance. Gastroenterology 2005; 129: $34-41$

[20] Frieling T, Neuhaus F, Heise J et al. Cap-assisted colonoscopy (CAC) significantly extends visualization in the right colon. Z Gastroenterol 2012; 50: 279-284

[21] Brenner H, Chang-Claude J, Seiler CM et al. Interval cancers after negative colonoscopy: population-based case control study. Gut 2012; 61: $1576-1582$

[22] Tada M, Nnoue H, Yabata E et al. Feasibility of the transparent capfitted colonoscope for screening and mucosal resection. Dis Colon Rectum 1997; 40: 618-621

[23] Matsushita M, Hajiro K, Okazaki K et al. Efficacy of total colonoscopy with a transparent cap in comparison with colonoscopy without the cap. Endoscopy 1998; 30: 444-447
[24] Dafnis G. Technical considerations and patient comfort in total colonoscopy with and without a transparent cap: initial experiences from a pilot study. Endoscopy 2000; 32: $381-384$

[25] Lee YT, Hin L, Hui AJ et al. Efficacy of cap-assisted colonoscopy in comparison with regular colonoscopy: a randomized controlled study. Am J Gastroenterol 2009; 104: 41-46

[26] Hewett DG, Rex DK. Cap-fitted colonoscopy: a randomized, tandem colonoscopy study of adenoma miss rates. Gastrointest Endosc 2010; 72: $775-781$

[27] Dai ], Feng N, Lu H et al. Transparent cap improves patient's tolerance of colonoscopy and shortens examination time by inexperienced endoscopists. J Dig Dis 2010; 11: $364-368$

[28] Tee HP, Corte C, Al-Ghamdi $\mathrm{H}$ et al. Prospective randomized controlled trial evaluating cap-assisted colonoscopy vs standard colonoscopy. World J Gastroenterol 2010; 16: 3905-3910

[29] Rastogi A, Bansal A, Rao DS et al. Higher adenoma detection rates with cap-assisted colonoscopy: a randomized controlled trial. Gut 2012; 61: 402-408

[30] Kondo S, Yamaji Y, Warabe $\mathrm{H}$ et al. A randomized controlled trial evaluation the usefulness of a transparent hood attached to the tip of the colonoscope. Am J Gastroenterol 2007; 102: 75 - 81

[31] Harada $\mathrm{Y}$, Hirsawa D, Fujita $\mathrm{N}$ et al. Impact of a transparent hood on the performance of total colonoscopy: a randomized controlled trial. Gastrointest Endosc 2009; 69: 637-644

[32] de Wijkerslooth TR, Stoop EM, Bossuyt PM et al. Adenoma detection with cap-assisted colonoscopy versus regular colonoscopy: a randomized controlled trial. Gut 2012; 61: 1426 - 1434

[33] Frieling T, Neuhaus F, Kuhlbusch-Zicklam R et al. Prospective and randomized study to evaluate the clinical impact of cap assisted colonoscopy (CAC). Z Gastroenterol 2013; 51: 1383-1388

[34] Pohl H, Bensen SP, Toor A et al. Cap-assisted colonoscopy and detection of adenomatous polyps (CAP) study: a randomized trial. Endoscopy 2015; 47: $891-897$

[35] Takeuchi Y, Inoue T, Hanaoka N et al. Autofluorescence imaging with a transparent hood for detection of colorectal neoplasms: a prospective, randomized trial. Gastrointest Endosc 2010; 72: 1006 - 1013

[36] Choi DH, Shin HK, Lee YC et al. Efficacy of transparent cap-attached colonoscopy: does it improve the quality of colonoscopy? J Korean Soc Coloproctol 2010; 26: 116-122

[37] Horiuchi A, Nakayama Y, Kajiyama M et al. Benefits and limitations of cap-fitted colonoscopy in screening colonoscopy. Dig Dis Sci 2013; 58: $534-539$

[38] Lee YT, Hul A], Wong VWS et al. Improved colonoscopy success rate with distally attached mucosectomy cap. Endoscopy 2006; 38: 739742

[39] Jadad AR, Moore RA, Caroll D et al. Assessing the quality of reports of randomized clinical trials: is blinding necessary? Control Clin Trials 1996; $17: 1-12$

[40] Berger VW. Is the Jadad score the proper evaluation of trials? J Rheumatol 2006; 33: 1710 - 1711

[41] Park SM, Lee SH, Shin KY et al. The cap-assisted technique enhances colonoscopy training: prospective randomized study of six trainees. Surg Endosc 2012; 26: 2939-2943

[42] Ng SC, Tsoi KK, Hirai HW et al. The efficacy of cap-assisted colonoscopy in polyp detection and cecal intubation: a meta-analysis of randomized controlled trials. Am J Gastroenterol 2012; 107: 1165-1173 